\title{
Effect of heat treatment on colour changes of black alder and beech veneers
}

\author{
Emilia-Adela Salca $^{1} \cdot$ Hikaru Kobori $^{2} \cdot$ Tetsuya Inagaki $^{3} \cdot$ Yoichi Kojima $^{2}$. \\ Shigehiko Suzuki ${ }^{2}$
}

Received: 14 September 2015/Accepted: 6 April 2016/Published online: 27 April 2016

(C) The Japan Wood Research Society 2016

\begin{abstract}
In the present study, colour changes in black alder (Alnus glutinosa L. Gaertn.) and beech (Fagus sylvatica L.) wood veneers subjected to heat treatment at $190{ }^{\circ} \mathrm{C}$ for different time spans were investigated. The potential of CIELab system and near infrared (NIR) spectroscopy were used to evaluate the colour changes. The changes in colour appeared mostly by the reduction in lightness which is related to the degradation of hemicelluloses during heat treatment in both wood species. It was found that black alder discoloured much more than beech veneers under same treatment conditions. NIR spectra revealed that the dark colour that wood veneers get under heat exposure is due to the chemical decomposition of lignin and hemicelluloses. Heat treatment could, therefore, enhance the use of such veneers for value added products in furniture manufacturing as an alternative to expensive tropical species.
\end{abstract}

Keywords Beech · Black alder - Heat treatment - Colour

Emilia-Adela Salca

emilia.salca@unitbv.ro

1 Faculty of Wood Engineering, Transilvania University of Brasov, Universitatii 1, 500068 Brasov, Romania

2 Department of Environment and Forest Resource Science, Faculty of Agriculture, College of Agriculture, Academic Institute, Shizuoka University, 836 Ohya, Suruga-ku, Shizuoka 422-8529, Japan

3 Graduate School of Bioagricultural Sciences, Nagoya University, Furo-cho, Chikusa-ku, Nagoya, Japan

\section{Introduction}

Heat treatment is an eco-friendly modification process applied to wood to obtain enhanced properties, such as improved dimensional stability [1-3], increased durability, resistance to fungi and natural weathering $[4,5]$, smooth surfaces [6,7], and also a decorative specific dark colour $[8,9]$. But besides the advantages it has, heat-treated wood presents reduced mechanical properties [10, 11]. Heattreated wood is used for a large variety of indoor and outdoor applications, namely: parquet, wall and ceiling panels, saunas, kitchens, decorations and utensils, fences, joinery, claddings, windows, doors, while for structural applications it is not recommended. A typical heat treatment process uses temperatures from 120 up to $250{ }^{\circ} \mathrm{C}$ for durations ranging from $15 \mathrm{~min}$ to $24 \mathrm{~h}$, depending on the process, species, sample size, moisture content and the desired target used. Chemical and physical properties of wood start to change during heat exposure at temperature of about $150{ }^{\circ} \mathrm{C}$ [12]. The decomposition of the main chemical compounds in wood occurs with high intensity at: $180{ }^{\circ} \mathrm{C}$ for hemicelluloses, $270{ }^{\circ} \mathrm{C}$ for lignin and $340{ }^{\circ} \mathrm{C}$ for cellulose [13]. Organic polymers and extractives found in wood may deteriorate when exposed to elevated temperatures [14]. Reactions producing red chromophores in wood were found responsible for red alder thermal darkening [15]. The wood colour changes due to heat are caused by thermal degradation of hemicelluloses and lignin. There are some differences between authors as regard to the temperature causing hydrolysis and oxidation of wood components. Such chemical changes may appear even at low temperature of about $65^{\circ} \mathrm{C}$, depending on $\mathrm{pH}$, moisture content, heating medium, exposure period and wood species [16]. Previous studies performed on solid wood have investigated the changes in wood colour that 
appeared during heat treatment and imply alteration of wood components [17-19]. The colour that wood gets after heat treatment was suggested to be an indicator of the degree of its modification and also a direct indication of chemical changes [20, 21]. Little information addressed the veneers modification of various wood species by heat treatment. Due to their small thickness, veneers need a shorter time of heat exposure at high temperature ranging between 180 and $200{ }^{\circ} \mathrm{C}$ during their thermo-densification process $[22,23]$. Such process when applied to solid wood is a fairly long process [23]. It was found that the densification process applied to veneers for a shorter time affected their surfaces, particularly colour changes [23].

It appeared that the convection heat treatment caused stronger discoloration on veneer surfaces regardless the wood species when compared to press heat treatment [22]. The dark colour of veneers can easily mask some blemishes and other discolorations on the surface. Various processes, such as staining and varnishing, which involve mainly chemicals, may be skipped when using heat treatment as an eco-friendly alternative to obtain dark colour veneers for furniture manufacturing.

Heat-treated veneers may be successfully used as overlaying material for composites used in furniture manufacturing [24].

Colour measurement and vibrational spectroscopy are non-destructive, rapid and low cost evaluation methods used to measure organic materials [25-30]. Recently near infrared (NIR) spectroscopy has been widely used for measuring various properties of wood [30]. Most of absorption band assignments for wood appeared in NIR region is summarised in the review [28]. Esteves and Pereira have demonstrated that NIR could predict several parameters including CIELab parameters and dimensional stability of heat-treated pine (Pinus pinaster) and eucalypt (Eucalyptus globulus) wood [25]. Gonzalez and Hale mentioned that physical properties of small specimens of heat-treated wood can be predicted with CIELab colour space measurement [26]. According to Sandak et al. cellulose and lignin content of archaeological oak wood were successfully predicted by NIR spectra with aid of partial least squares regression (PLSR) analysis [27]. It was found that such methods may be integrated in the production line in wood industry and also for heat-treated wood with a view to assess the wood quality. Apart of CIELab colour measurement which was shown to give significant correlations with milled wood, NIR spectroscopy offers multiple advantages of allowing predictions for wood properties, like moisture content, density and stiffness [25]. NIR spectrum of the heat-treated wood gave information on the process extent and also on the wood relevant properties and uses. Therefore, NIR technique is a powerful tool used to determine chemical composition and to detect physical, mechanical and anatomical properties of wood materials [30].

The objective of this study was to evaluate the colour changes that occurred on wood veneers when subjected to heat treatment by using the CIELab colorimetry technique and NIR spectroscopy. In the present study, colour changes in black alder (Alnus glutinosa L. Gaertn.) and beech (Fagus sylvatica L.) wood veneers were investigated. The two wood species are differently set within the Romanian hardwood classification, namely: black alder is a less valuable wood resource but a fast growing species, while beech represents one of the most common wood species in wood industry. When applied to such veneer species, heat treatment could therefore enhance their use for value added products in furniture manufacturing as an alternative to expensive tropical species.

\section{Materials and methods}

Two wood species, namely black alder (Alnus glutinosa L. Gaertn.) and beech (Fagus sylvatica L.) were used in this study. Defect free veneer samples were cut from commercially manufactured veneers supplied by Losan Company in Romania. Samples had the dimensions of $70 \mathrm{~mm}$ by $70 \mathrm{~mm}$ by $0.5 \mathrm{~mm}$. A total of twenty samples were cut for each species. Prior to heat treatment all samples were conditioned for 1 week at $20{ }^{\circ} \mathrm{C}$ and $60 \% \mathrm{RH}$. The moisture content of samples was $7.5 \%$. Five groups, each of four specimens, were prepared. Out of them, one group was kept as reference while the others were subjected to heat treatment in a regular oven at $190{ }^{\circ} \mathrm{C}$ with different time spans for 5, 10, 20 and $40 \mathrm{~min}$, respectively.

\section{Colour measurement of the samples}

A Chroma Meter Konika Minolta CR-400 device was used for colour measurements. For each sample three colour measurements were made in randomly selected zones, according to ISO 7724-2 standard [31]. CIELab System was used for colour evaluation [32]. $L^{*}, a^{*}$ and $b^{*}$ colour coordinates were determined both for control group and heat-treated veneers. Hereinafter, the colour differences $\left(\Delta L^{*}, \Delta a^{*}\right.$ and $\left.\Delta b^{*}\right)$ and then the total colour change $\Delta E^{*}$ were calculated, according to the following relations:

$$
\begin{aligned}
& \Delta L^{*}=L_{E}^{*}-L_{i}^{*} \\
& \Delta a^{*}=a_{E}^{*}-a_{i}^{*} \\
& \Delta b^{*}=b_{E}^{*}-b_{i}^{*} \\
& \Delta E^{*}=\sqrt{\left(\left(\Delta L^{*}\right)^{2}+\left(\Delta a^{*}\right)^{2}+\left(\Delta b^{*}\right)^{2}\right)}
\end{aligned}
$$


where $L^{*}$ is the degree of lightness; $a^{*}$ degree of redness and greenness; $b^{*}$ degree of yellowness and blueness, and the subscripts $E$ and $i$ indicate the values for the exposed samples and control references, respectively.

\section{NIR measurement of the samples}

Diffuse reflectance NIR spectra were achieved from the surface of veneers by using a Fourier Transform near infrared (FT-NIR) spectrometer MatrixF-Bruker Optics. The measured NIR spectra ranged between 10,000 and $4000 \mathrm{~cm}^{-1}$ with $3.85 \mathrm{~cm}^{-1}$ interval. The spectral resolution was set to $8 \mathrm{~cm}^{-1}$. FT-NIR measurements were performed three times on each sample in randomly selected zones in a climatic chamber. Each spectrum was achieved as an average of 32 scans. Bands were assigned as indicated by Schwanninger et al. [28]. The second derivative was computed by gap-segment derivative (segment $=7$, gap $=3$ point) to eliminate the baseline drift and separate the overlap of absorption peaks. PLSR was then applied to build the predictive models for $L^{*} a^{*} b^{*}$ values. Each variable was mean centred and the maximum number of latent variable (LV) was set to five. Four third of data sets were randomly selected as calibration set and remaining data were used for test set validation. The optimum number of LV was determined where the minimum standard error of validation (SEV) was obtained. Data were processed by Matlab R2014a.

\section{Results and discussions}

\section{Colour changes during heat treatment}

When wood is heated, its colour changes to yellow, brown, red or grey. Whatever the species, heat-treated wood darkening depends on treatment schedule. Based on visual observations, the surface colour of heat-treated samples changed from lighter to darker with increasing the exposure time, but with different rates. Surface colour changes under different heating durations for black alder and beech veneers are shown in Fig. 1. The surface colour changes of veneers due to heat treatment were investigated using the CIELab colour space. Table 1 presents the average values of $L^{*}, a^{*}$ and $b^{*}$ colour coordinates for control and heattreated specimens of the investigated wood species. A decrease in lightness $L^{*}$ with a similar trend for both species under study was noticed. In particular, lightness $L^{*}$ values monotonously decreased the first $10 \mathrm{~min}$ of heat exposure at $190{ }^{\circ} \mathrm{C}$. Afterwards the overall colour became darker as the heating time increased up to $40 \mathrm{~min}$. The change in lightness was more pronounced for black alder than for beech veneers. Such darkening but at a slight rate was also reported for birch, alder and pine veneer specimens during their thermo-densification process for $4 \mathrm{~min}$ at temperature of $200{ }^{\circ} \mathrm{C}$ and pressure ranging from 4 to $12 \mathrm{MPa}$, while almost no changes appeared for beech samples at the same parameters [23]. Oak veneers subjected to oven heat treatment at $200{ }^{\circ} \mathrm{C}$ for 10,20 and $30 \mathrm{~min}$ also showed a significant surface darkness when compared to press treatment [22]. Moreover, the feasibility of predicting some wood properties using lightness values, such as swelling, equilibrium moisture content, decay resistance and modulus of rupture (MOR), was previously reported [5, 26, 29]. The process of discoloration is due to the changes which take place in extractives, lignin and hemicelluloses. That behaviour is always accompanied by a reduction in lightness. Previous studies reported that decrease in lightness was caused by a decrease in hemicellulose contents, especially pentosan [16-18]. Extractives of each wood species make a specific colour which is expressed by two chromatic parameters, namely $a^{*}$ and $b^{*}$. It is fact that the red component of wood is highly associated with the extractive content in wood [33, 34]. Figure 2 shows that the colour coordinates, $a^{*}$ and $b^{*}$, respected almost the same pattern trend with the decrease in lightness for both species. The redness coordinate $a^{*}$ increased gradually for each time span during the heat treatment for both species here investigated. It appeared that black alder veneers became redder than beech samples
Fig. 1 Visual appearance of black alder and beech veneers as function of heat treatment $\left(T^{\circ} \mathrm{C} / \mathrm{min}\right)$
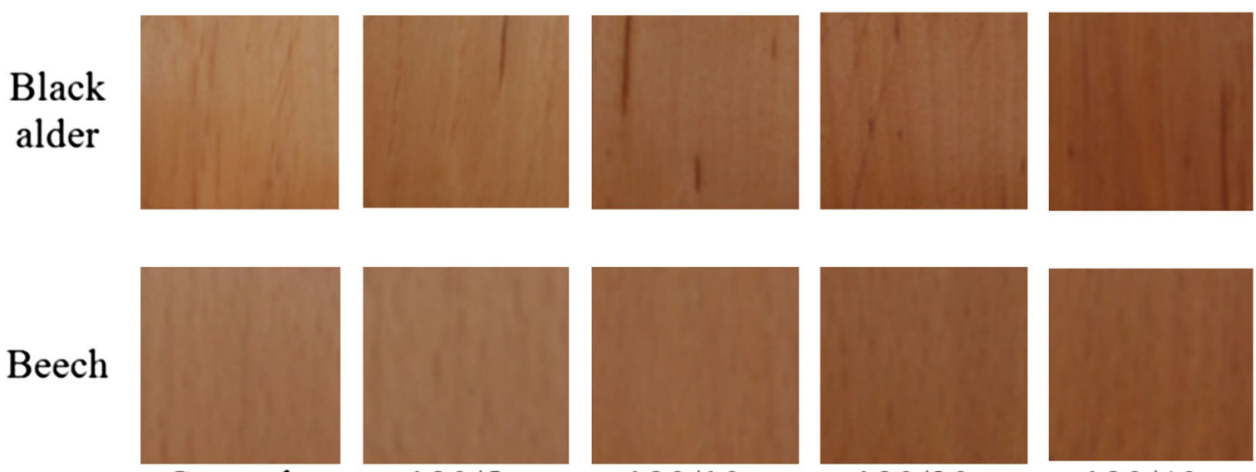

Control

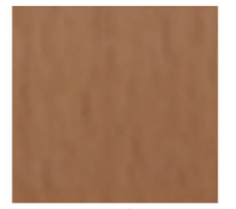

$190 / 5$

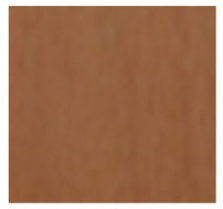

$190 / 10$

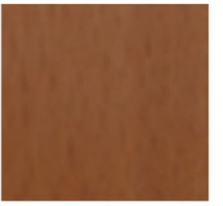

$190 / 20$

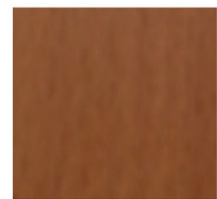

$190 / 40$ 
Table 1 Colour coordinates of black alder and beech veneers before and after heat treatment

\begin{tabular}{llllll}
\hline Wood species & Heat treatment (temperature/time) & \multicolumn{2}{l}{ Colour coordinates } & \multirow{2}{*}{$\Delta E^{*}$} \\
\cline { 3 - 5 } & $\left(T^{\circ} \mathrm{C} / \mathrm{min}\right)$ & \multicolumn{1}{l}{$L^{*}$} & \multicolumn{1}{l}{$a^{*}$} & \multicolumn{1}{l}{$b^{*}$} \\
\hline Black alder & Control sample & $70.81(1.65)$ & $8.42(0.60)$ & $25.78(0.28)$ & - \\
& $190 / 5$ & $68.72(1.67)$ & $8.79(0.56)$ & $25.37(0.58)$ & 2.16 \\
& $190 / 10$ & $66.38(1.72)$ & $9.40(0.50)$ & $25.04(0.80)$ & 4.59 \\
& $190 / 20$ & $60.69(1.29)$ & $10.41(0.27)$ & $25.38(0.58)$ & 10.32 \\
& $190 / 40$ & $57.05(1.16)$ & $10.67(0.23)$ & $23.97(1.04)$ & 14.06 \\
Beech & Control sample & $70.47(0.28)$ & $7.61(0.18)$ & $21.51(0.26)$ & - \\
& $190 / 5$ & $69.27(0.27)$ & $7.86(0.18)$ & $22.28(0.42)$ & 1.45 \\
& $190 / 10$ & $67.55(0.81)$ & $8.51(0.26)$ & $22.21(0.45)$ & 3.13 \\
& $190 / 20$ & $64.62(0.38)$ & $9.48(0.20)$ & $24.43(0.58)$ & 6.80 \\
& $190 / 40$ & $60.07(1.58)$ & $10.45(0.39)$ & $22.86(0.58)$ & 10.86 \\
\hline
\end{tabular}

Values in parenthesis are standard deviations

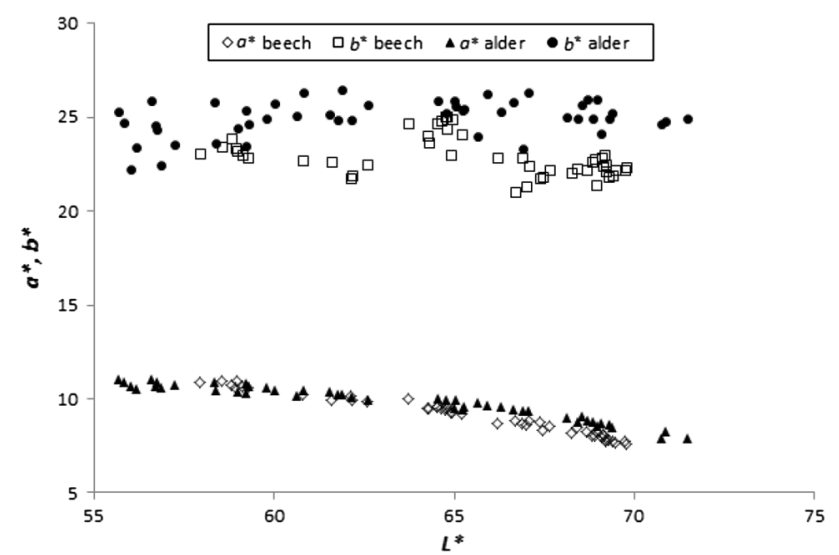

Fig. 2 Relation between $a^{*}$ and $b^{*}$ colour coordinates and $L^{*}$ in heattreated veneers, plotted irrespective of exposure conditions

as the duration of heating process increased to $20 \mathrm{~min}$. At the end of treatment both veneer species recorded almost same values of the red-green chromaticity $\left(a^{*}=10.67\right.$ for black alder and $a^{*}=10.45$ for beech). Bekhta et al. determined that beech veneers showed a tendency to become redder while alder veneers became greener during the densification process at $200{ }^{\circ} \mathrm{C}$ [23]. On the other hand, it is well known that wood species of Alnus changes from a light-pinkish colour to a red/orange colour on exposure to air, which is caused by Maillard reactions between sugars and amino acids/proteins in wood [15]. Therefore, it was suggested that thermal modification of colour in red alder involves certain reactions which produce orange/red chromophoric groups in wood [15]. The yellow colour component of wood is influenced particularly by the photochemistry of lignin. Also lignin derivates, such as quinone and stilbenes generate the yellowing process [34]. Different variations of $b^{*}$ values for the two wood species under study were noticed. In case of black alder veneers, the direction of colour modification for $b^{*}$ coordinate respected a decreased linear trend during the first $10 \mathrm{~min}$ of heat exposure, while for beech veneers an increase of yellow coordinate was noticed for the first $5 \mathrm{~min}$ of exposure. Next $5 \mathrm{~min}$ of heat exposure did not affect the yellow coordinate for beech veneers. The situation changed after that and for both species an increase of yellow coordinate was recorded at 20-min time span of exposure. At this point, the description of the colour evolution may be explained as an orange darkening considering the progress of colour chromaticity expressed by $a^{*}$ and $b^{*}$ coordinates. The same decreasing trend of yellow coordinate was observed during last time span of heat exposure for both veneer species. A similar evolution of the yellow colour component for thermo-densified veneers was mentioned by Bekhta et al. [23]. Such increase and decrease in colour coordinates $a^{*}$ and $b^{*}$, for different heat treatment conditions, have been also reported for various wood species such as spruce, pine, oak, poplar, birch, sugi, keyaki, acacia $[5,8,17,19,22]$.

The partial colour differences $\Delta L^{*}, \Delta a^{*}$ and $\Delta b^{*}$ and the total colour differences $\Delta E^{*}$ depended on the heat treatment conditions. For both investigated wood veneers, the lightness difference $\Delta L^{*}$ trend decreased with increasing the heating time. The largest absolute value of lightness difference $\Delta L^{*}$ was observed at the longest heat exposure time of 40 min for black alder veneers $\left(\Delta L^{*}=-13.76\right.$ for black alder and $\Delta L^{*}=-10.40$ for beech). Important chromatic differences for redness variation were noticed in the case of beech veneers $\left(\Delta a^{*}=2.84\right)$ when compared to black alder veneers $\left(\Delta a^{*}=2.25\right)$ for 40 -min time span of heat exposure. A strong (Pearson) correlation of $\Delta a^{*}$ with the lignin content was mentioned for heat-treated beech while the smallest correlation between colour differences and chemical changes was found with cellulose [18]. The chromatic differences of yellowness recorded at 20-min time span of heat exposure presented for beech veneers the highest value 
Fig. 3 Second derivative spectra of black alder veneers as function of heat exposure (a); detail of second derivative spectra (b)
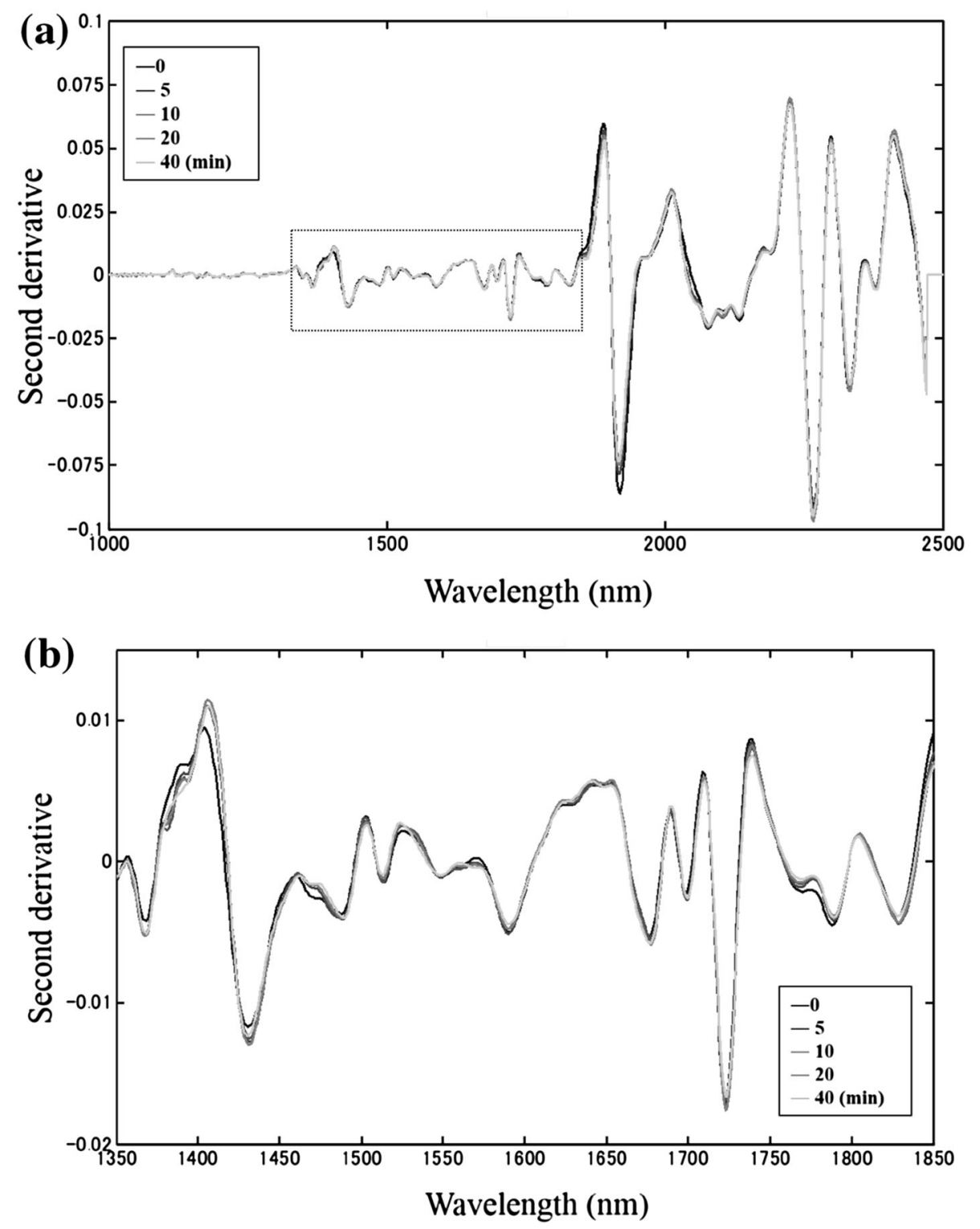

Table 2 Summary of PLSR model

\begin{tabular}{llllllll}
\hline Wood species & Objective & LV & $R_{\mathrm{c}}^{2}$ & $R_{\mathrm{v}}^{2}$ & SEC & SEV & RPD \\
\hline Black alder & $L^{*}$ & 5 & 0.94 & 0.79 & 1.30 & 2.02 & 2.34 \\
& $a^{*}$ & 5 & 0.90 & 0.68 & 0.30 & 0.43 & 1.92 \\
\multirow{5}{*}{ Beech } & $b^{*}$ & 2 & 0.22 & 0.22 & 0.88 & 0.85 & 0.98 \\
& $L^{*}$ & 5 & 0.85 & 0.71 & 1.35 & 2.00 & 2.01 \\
& $a^{*}$ & 5 & 0.82 & 0.75 & 0.42 & 0.51 & 2.15 \\
& $b^{*}$ & 2 & 0.22 & 0.47 & 0.88 & 0.74 & 1.48
\end{tabular}

$L V$ number of latent variables, $R_{c}^{2}$ determinant coefficient for calibration, $R_{v}^{2}$ determinant coefficient for test set validation, $S E C$ standard error for calibration, $S E V$ standard error for test set validation, $R P D$ ratio of performance (SD/SEV) among the two wood species $\left(\Delta b^{*}=2.92\right)$. The largest changes in total colour differences $\Delta E^{*}$ were observed at the end of the treatment, at 40-min time span of heat exposure for both veneer species (Table 1). It was reported that the changes in $L^{*}$ and $\Delta E^{*}$ of hinoki had similar degree to those of cellulose during heat treatment at $180^{\circ} \mathrm{C}$. Carbonyl groups in the cellulose chains and the formation of low molecular substances (furan type) were estimated as being responsible for the colour changes [21]. Moreover, total changes of colour in thermally modified wood originates from chemical changes more in lignin than in polysaccharides, due to the darkening of lignin itself, which is associated with the generation of chromophoric groups [18]. 
Fig. 4 Loadings for first three components of PLSR for $L^{*}$ prediction models (a) black alder (b) beech

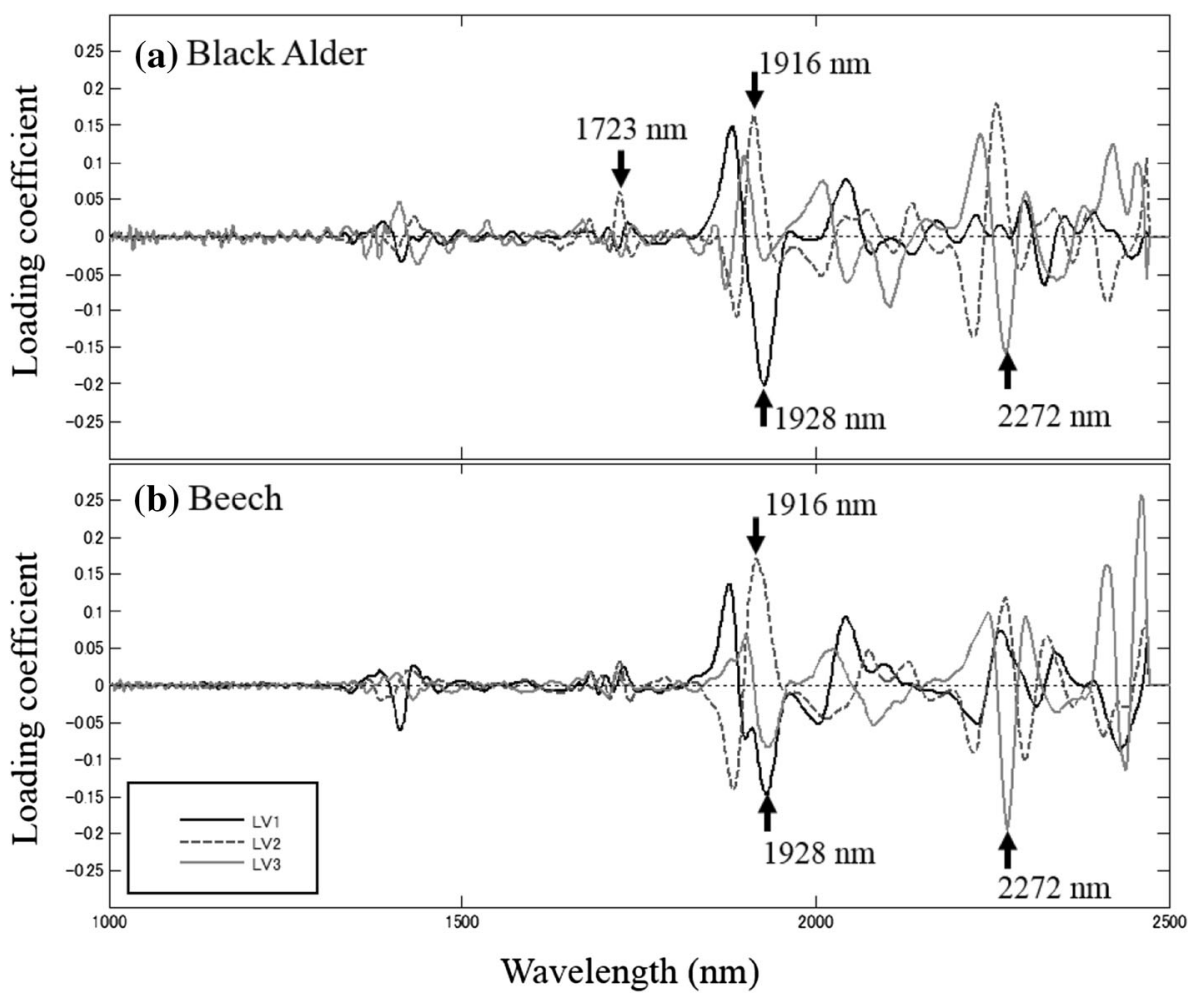

\section{NIR spectra and PLSR analysis}

Heat-treated black alder and beech veneers after different time spans of heat exposure at $190{ }^{\circ} \mathrm{C}$ have been compared to control specimens. Changes of absorption bands were analysed in relation with the increase of heat exposure. Chemical changes due to heat treatment occurred for both wood species under study. Figure 3 presents the FT-NIR second derivative spectra of black alder veneers for various time spans of heat exposure. Hemicelluloses (band $1725 \mathrm{~nm}$ ) were mostly affected by heat treatment as the heat exposure increased. It represents the first overtone of $\mathrm{C}-\mathrm{H}$ stretching vibrations and is related to the hemicelluloses degradation [35]. The effect of thermal exposure on hardwoods is associated to their higher acetyl and hemicellulose content [36]. Crystalline cellulose (1552 and $1589 \mathrm{~nm}$ ) was slightly affected when compared to amorphous regions of cellulose $(1428 \mathrm{~nm})$. A higher resistance of cellulose when compared to hemicelluloses under heat exposure was noticed. Esteves and Pereira reported that the glucose rate in hydrolysates increased under heating due to hemicellulose degradation [12]. Some shifts and changes in the case of lignin were noticed (band $1673 \mathrm{~nm}$ ). Deciduous lignin having guaiacyl and syringyl units is less stable than coniferous one which contains mainly guaiacyl units [27]. The lignin content increased with the increasing of heat exposure. Such increase in apparent lignin content related to the effect of polycondensation reactions with other components in the cell wall, which generated further crosslinking [36]. For both wood species here investigated changes in absorbance were observed for hemicellulose (1350, 1725, $2139 \mathrm{~nm})$, cellulose $(1368,1428,1589,1788$, $2081 \mathrm{~nm})$ and lignin $(1673,1702,2272 \mathrm{~nm})$. Regarding the correlation between spectra and heat exposure and CIELab coordinates it was noticed the largest spectral variation at absorptions due to water $(1919 \mathrm{~nm})$ and hemicellulose $(2139 \mathrm{~nm})$. PLSR analysis was used to predict and express the colour coordinates by linear combination of absorbance at each wavenumber. A summary of PLSR model is presented in Table 2. Prediction models obtained for lightness $L^{*}$ and redness $a^{*}$ showed proper accuracy while the yellowness could not be predicted. Better coefficients were achieved for black alder veneers (Table 2). In case of yellowness prediction, samples were separated into two groups, namely: control and heat treated. This indicates there is great difference between untreated and heat-treated spectra while there is no great difference among heat treatment exposures. Figure 4 shows the first three loadings for lightness $L^{*}$ prediction model. As shown in Fig. 4, higher loading coefficient appeared at the wavelength range longer than $1800 \mathrm{~nm}$. This may be due to the higher $S / N$ ratio in longer wavelength region having stronger absorption. For both wood species, black alder and beech, the highest absolute value of LV1and LV2 loading coefficient was observed at 1928 and $1916 \mathrm{~nm}$, respectively. These regions are close to water absorption. This might be 
due to the indirect relationship between moisture content and lightness $L^{*}$. Based on hygroscopic properties of wood, the equilibrium moisture content decreased with the increase of thermal treatment exposure. There are many additional wavelengths related to lignin which contributed to lightness $L^{*}$ prediction.

For both wood species, LV3 loading at $2272 \mathrm{~nm}$, which is assigned to lignin, showed almost the same negative value. In addition, in case of black alder, LV2 loading at $1723 \mathrm{~nm}$, which is assigned to hemicellulose, showed relatively high value in shorter wavelength region, while that for beech did not show any significant value. Effects of cellulose changes due to heat treatment on lightness $L^{*}$ may differ between wood species.

\section{Conclusions}

The study investigated the colour changes in black alder and beech veneers subjected to heat treatment at $190{ }^{\circ} \mathrm{C}$ for different time spans. The progress of discoloration depended on each wood species. The changes in colour were caused mostly by the reduction in lightness which related to the degradation of hemicelluloses during heat treatment in both wood species. It was found that black alder discoloured much more than beech veneers under same treatment conditions. Moreover, prediction models by NIR for lightness and redness colour coordinates showed prediction accuracy. Heat treatment could therefore enhance the use of such wood species for value added products in furniture manufacturing as an alternative to expensive tropical species.

Acknowledgments This research is part of a project developed under a Fellowship offered by Asia Bridge Program at the Faculty of Agriculture from Shizuoka University. The authors acknowledge the support received from Shizuoka University and Nagoya University in Japan, Losan Company and Forest Products Laboratory from Transilvania University Brasov in Romania to perform this study.

\section{References}

1. Kocaefe D, Shi JL, Yang DQ, Bouazara M (2008) Mechanical properties, dimensional stability, and mold resistance of heattreated jack pine and aspen. For Prod J 58(6):88-93

2. Zivkovic V, Prsa I, Turkulin H, Sinkovic T, Jirou-Rajkovic V (2008) Dimensional stability of heat treated wood floorings. Drvna Industrija 59(2):69-73

3. Bak M, Nemeth R (2012) Changes in swelling properties and moisture uptake rate of oil-heat-treated poplar (Populus $\times \mathrm{Eu}$ ramericana CV. Pannonia) wood. Bioresources 7(4):5128-5137

4. Yildiz S, Yildiz UC, Tomak ED (2011) The effects of natural weathering on the properties of heat-treated alder wood. Bioresources 6(3):2504-2521

5. Guo F, Huang R, Lu J, Chen Z, Cao Y (2014) Evaluating the effect of heat treating temperature and duration on selected wood properties using comprehensive cluster analysis. J Wood Sci 60:255-262

6. Unsal O, Ayrilmis N (2005) Variations in compression strength and surface roughness of heat-treated Turkish river red gum (Eucalyptus camaldulensis) wood. J Wood Sci 51:405-409

7. Salca EA, Hiziroglu S (2014) Evaluation of hardness and surface quality of different wood species as function of heat treatment. Mater Des 62:416-423

8. Tuong VM, Li J (2010) Effect of heat treatment on the change in colour and dimensional stability of acacia hybrid wood. Bioresources 5(2):1257-1267

9. Nemeth R, Ott A, Takats P, Bak M (2013) The effect of moisture content and drying temperature on the color of two poplars and Robinia wood. Bioresources 8(2):2074-2083

10. Kubojima Y, Okano T, Ohta M (2000) Bending strength and toughness of heat-treated wood. J Wood Sci 46:8-15

11. Korkut S, Hiziroglu S (2009) Effect of heat treatment on mechanical properties of hazelnut wood (Curylus colurna L.). Mater Des 30(5):1853-1858

12. Esteves MB, Pereira HM (2009) Wood modification by heat treatment. A review. Bioresources 4(1):370-404

13. Bobleter O, Binder H (1980) Dynamic hydrothermal degradation of wood. Holzforschung 34:48-51

14. Hu C, Jiang G, Xiao M, Zhou J, Yi X (2012) Effects of heat treatment on water-soluble extractives and color changes of merbau heartwood. J Wood Sci 58:465-469

15. Thompson DW, Kozak RA, Evans PD (2005) Thermal modification of color in red alder veneer. 1. Effects of temperature, heating time and wood type. Wood Fiber Sci 37(4):653-661

16. Sandoval-Torres S, Jomaa W, Marc F, Puiggali JR (2010) Causes of color changes in wood during drying. For Stud China 12(4):167-175

17. Bekhta P, Niemz P (2003) Effect of high temperature on the change in colour, dimensional stability and mechanical properties of spruce wood. Holzforschung 57:539-546

18. Gonzalez-Pena MM, Hale MDC (2009) Colour in thermally modified wood of beech, Norway spruce and Scots pine. Part 1: colour evolution and colour changes. Holzforschung 63:385-393

19. Matsuo M, Umemura K, Kawai S (2014) Kinetic analysis of color changes in keyaki (Zelkova serrata) and sugi (Cryptomeria japonica) wood during heat treatment. J Wood Sci 60:12-20

20. Sundqvist B, Karlsson O, Westermark U (2006) Determination of formic-acid and acetic acid concentrations formed during hydrothermal treatment of birch wood and its relation to colour, strength and hardness. Wood Sci Technol 40:549-561

21. Matsuo M, Umemura K, Kawai S (2012) Kinetic analysis of colour changes in cellulose during heat treatment. J Wood Sci 58(2):113-119

22. Denes L, Lang E (2013) Photodegradation of heat treated hardwood veneers. J Photochem Photobiol B 118:9-15

23. Bekhta P, Proszyk S, Krystofiak T (2014) Colour in short-term thermo-mechanically densified veneer of various wood species. Eur J Wood Wood Prod 72(6):785-797

24. Murata K, Watanabe Y, Nakano T (2013) Effect of thermal treatment of veneer on formaldehyde emission of poplar plywood. Materials 6:410-420

25. Esteves B, Pereira H (2008) Quality assessment of heat treated wood by NIR spectroscopy. Holz Roh Werkst 66(5):323-332

26. Gonzalez-Pena MM, Hale MDC (2009) Colour in thermally modified wood of beech, Norway spruce and Scots pine. Part 2: property prediction from colour changes. Holzforschung 63:394-401

27. Sandak A, Sandak J, Zborowska M, Pradzynski W (2010) Near infrared spectroscopy as a tool for archaeological wood characterization. J Archaeol Sci 37:2093-2101 
28. Schwanninger M, Rodrigues JC, Fackler K (2011) A review of band assignments in near infrared spectra of wood and wood components. J Near Infrared Spectrosc 19:287-308

29. Todorovic N, Popovic Z, Milic G, Popadic R (2012) Estimation of heat-treated beech wood properties by colour change. Bioresources 7(1):799-815

30. Tsuchikawa S, Kobori H (2015) A review of recent application of near infrared spectroscopy to wood science and technology. J Wood Sci 61:213-220

31. ISO 7724-2 (1984) Paints and varnishes. Colorimetry. Part 2: colour measurement. International Organization for Standardization, Geneva, p 6

32. McLaren K (1976) The development of the CIE $1976\left(L^{*} a^{*} b^{*}\right)$ uniform colour-space and colour-difference formula. J Soc Dyers Colour 92:338-341
33. Gierlinger N, Jacques D, Grabner M, Wimmer R, Schwanninger M, Rozenberg P, Paques LE (2004) Colour of larch heartwood and relationships to extractives and brown-rot decay resistance. Trees 18(1):102-108

34. Yazaki Y, Collins PJ, Mccombe B (1994) Variations in hot water extractives content and density of commercial wood veneers from blackbutt (Eucalyptus pilularis). Holzforschung 48:107-111

35. Schwanninger $M$, Hinterstoisser $B$, Gierlinger $N$, Wimmer R, Hanger J (2004) Application of Fourier Transform near infrared spectroscopy (FT-NIR) to thermally modified wood. Holz Roh Werkst 62:483-485

36. Hill C (2006) Wood modification-chemical, thermal and other processes. Wiley Series in renewable resources. Wiley, Chichester 